\title{
Economic analysis of the wastewater treatment plant
}

\author{
Heni Fitriani $^{1 *}$, Febriansyah Putra $^{1}$, and Ika Juliantina ${ }^{1}$ \\ ${ }^{1}$ Department of Civil Engineering, Universitas Sriwijaya, Sumatera Selatan, Indonesia
}

\begin{abstract}
Problems in municipal and domestic wastewater have become major issues in sanitation sectors. One of the solutions to overcome domestic sewage is to install the Wastewater Treatment Plant (WWTP). Economic analysis is fundamentally required for its viability. This paper focused on the economic analysis of feasible rates determination based on the ability to pay (ATP) and willingness to pay (WTP) of users. Furthermore, this paper also highlighted the sensitivity of NPV for different scenarios using different discount rates. Field questionnaires were distributed to surrounding communities in the study area. It was found that the values of ATP and WTP were IDR 125,000 and 40,000 respectively. Using the higher values of ATP, the NPV, and BCR were found to be economically feasible. For the sensitivity analysis, the results showed positive NPV using interest rates of 7.75-9.25\%, and negative NPV for discount rates up to $9.75 \%$. Therefore, to implement the development of WWTP, subsidies from the local government may help the starting point of the wastewater treatment plans construction and its operation and maintenance costs.
\end{abstract}

\section{Introduction}

According to [7], there were approximately $54 \%$ of the world's population live in urban areas. Due to population growth, problems in sanitation and environment increase significantly. Wastewater Treatment Plant (WWTP) is a form of treatment to sanitation issues concerning domestic and non-domestic sewage. However, the construction of WWTP requires a considerable cost as well as the maintenance and operational costs. Due to lack of financial resources, it is essential to analyze the economic feasibility to determine whether the project is feasible or not.

Researches on the economic analysis of wastewater treatment plants have been emerging for many decades [2-3], [5-6], [9]. The work reported by [6] focused on Economic Efficiency Analysis (EEA) and Life Cycle Assesment (LCA) of WWTP by evaluating several WWTP processes. This study found that there is a potential of using EEA and LCA for an integrated waste management system. Reference [8] analyzed the economic feasibility of wastewater systems by using a neural network. This method was

\footnotetext{
*Corresponding author: henifitriani79@yahoo.com
} 
believed to be more simple and more economical to select the optimum solutions for wastewater systems.

Meanwhile, reference [4] studied the feasibility analysis of wastewater by comparing several variations of prices to measure the investment costs. The work by [9] emphasized the customer preferences for service and willingness to pay at water company using a stated preference. However, the work by [11] focused on the planning system on distribution and management of domestic wastewater treatment.

Identifying the customers' income is essential to measure the Willingness to Pay (WTP) WTP and Ability to Pay (ATP) [1]. WTP is defined as the willingness of users to issue a reward for services or facilities for its use. WTP is determined by the user perception on the quality of the level of service, user's utility to services, facilities provided, and the user's income. Meanwhile, ATP is based on the income of the users per month, the percentage of costs to pay the total fees, and the numbers of family members of users or customers. Therefore, the WTP and ATP are essential to analyze the feasibility of WWTP development plan. The construction of WWTP in the district of Muara Enim, South Sumatra was undertaken as a case study. The wastewater treatment plant is centralized and integrated within the area of settlements. It is expected the sanitation problems in this area can be resolved. This paper focused on the economic analysis of possible rates based on the ability of users to pay (ATP) and willingness to pay (WTP). This paper also highlighted the sensitivity of NPV of some scenarios using different discount rates.

\section{Methodology}

This research was conducted in the Residential Growth Areas at Muara Enim in the Province of South Sumatra with total areas of 82.16 hectares and a population of 2356 . Three areas for the wastewater treatment plant were identified for plans based on the proximity of the water resources. Fig. 1 exhibited the research area as shown by the dotted line covering the whole areas for the Growth Residential Areas. The economic feasibility analysis was conducted by examining three indicators namely Net Present Value (NPV), Internal Rate of Return (IRR), and Benefit Cost Ratio (BCR) methods. The variables used in this research consist of land costs, construction costs, operational and maintenance costs, and revenue from users. In this study, the rates were analyzed based on the ability to pay (ATP) and willingness to pay (WTP) of the users. To examine the influences of the most significant variables, it is necessary to analyze the sensitivity of each variable by using the sensitivity analysis. The details for data collection can be seen in Fig. 2.

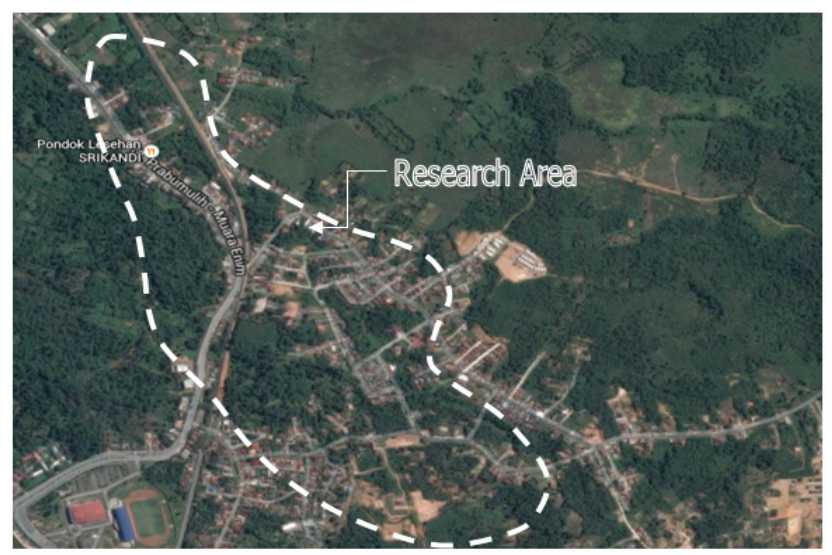

Fig. 1. The study area in the growth residential areas at Muara Enim, South Sumatra. 


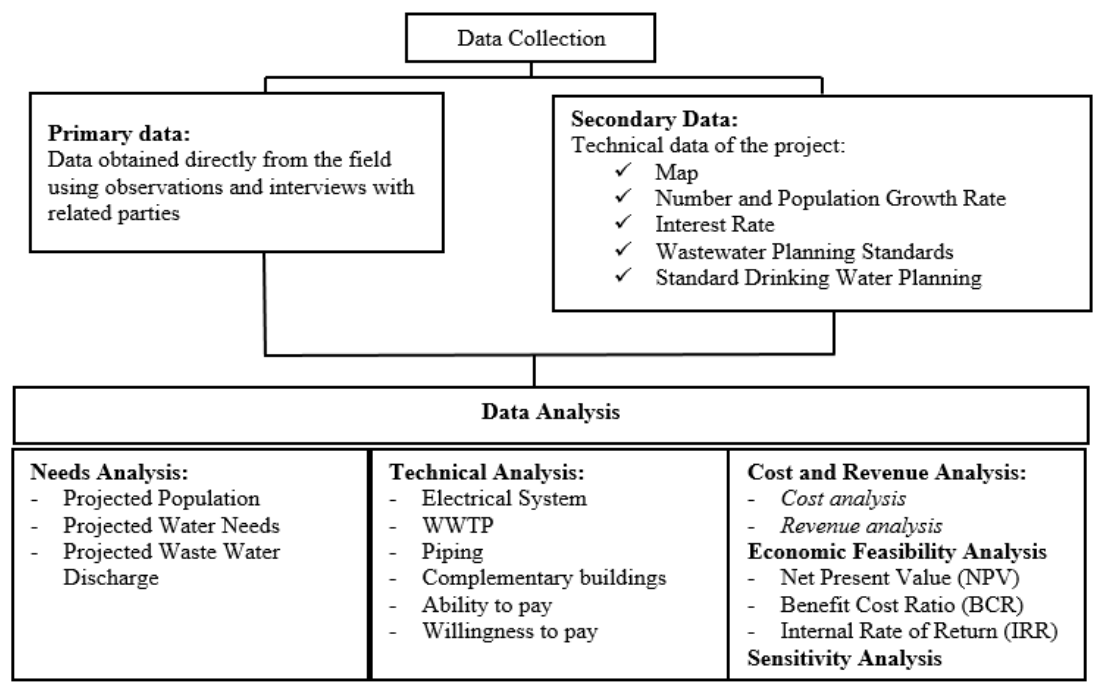

Fig. 2. Flow chart for data collection and data analysis.

Variables used in this research are 1) Land Acquisition Costs. Land acquisition costs are investment costs incurred at the beginning of the implementation of project for the location of wastewater treatment plants. 2) Construction Costs. Components of construction costs cover the cost of planning, physical development, and supervision of the construction work. Construction is generated at the development stage of the structure of WWTP, pipelines, and other complementary building. 3) Operation and Maintenance (O\&M) Costs. Cost of operation and maintenance (O\&M) is the cost incurred for the operation and maintenance of WWTP, and its piping network control tanks, flushing facilities, and the installation of house connections. 4) Revenues from Users. The taxes represent the income received from the payment service from the users from their households to the wastewater treatment plant. 5) Revenues from Retribution Services. The revenues represent the income generated from the users due to the services every month.

The questionnaires survey was conducted to the selected respondents to determine the values of ATP and WTP. The respondents of this research were divided into three clusters according to the WWTP service locations: (a) Cluster 1 (Road of Ade Irma Suryani), (b) Cluster 2 (Road of Pematang Sayap II), and (c) Cluster 3 (Road of Ayek Putih III).

Table 1. Number of households and population in each area.

\begin{tabular}{|c|c|c|c|}
\hline No & Locations & $\begin{array}{c}\text { Number of } \\
\text { Households }\end{array}$ & $\begin{array}{c}\text { Population in } \\
\text { total }\end{array}$ \\
\hline 1 & Road of Ade Irma Suryani & 143 & 734 \\
\hline 2 & Road of Pematang Sayap II & 109 & 559 \\
\hline 3 & Road of Ayek Putih III & 207 & 1063 \\
\hline \multicolumn{2}{|c|}{ Amount } & 459 & 2,356 \\
\hline
\end{tabular}

Table 1 showed the number of households and the total population in the study area. However, the sample size was counted using the formula given below. Based on Table 1 above, it is known that the numbers of the households in each area accounted for 459 . Therefore, the number of samples can be determined as follows: 


$$
n=\frac{459}{1+459 .(0.1)^{2}}=82.11 \approx 100 \text { households }
$$

As a result, the total respondents were appoximately 82 people (Eq. 1). Eventough the calculated respondents were about 82 respondents, however a total of 100 respondents were taken in the study to anticipate the missing data and to increase the level of confidence.

\section{Results and discussion}

\subsection{Analysis of wastewater rates}

Wastewater rates analysis was used to define the values of Willingness to Pay (WTP) and Ability to Pay (ATP) wastewater treatment plant (WWTP) users. Based on the analysis from 100 respondents, it was found that $34 \%$ of respondents could pay IDR 31,000 up to 40,000 per month. Meanwhile, only $9 \%$ were willing to pay in between IDR 41,000-50,000 per month. Since most respondents' WTP were between IDR 31,000 and 40,000, therefore, the maximum value of WTP for the analysis was assumed to be IDR 40,000 as seen in Table 2, Table 3, and 4 presented the percentages of revenues and expenditures of users' monthly income based on the survey. It was found that $60 \%$ of users' revenues had more than IDR 5 million per month. Meanwhile, only $15 \%$ of the total income was spent above IDR 5 million. 33\% of respondents' expenditure was about IDR 3-3.5 million per month.

Table 2. Willingness to Pay (WTP) based on survey.

\begin{tabular}{|c|c|c|}
\hline Willingness to Pay (IDR) & Numbers of respondents & Percentage (\%) \\
\hline$<20,000$ & 30 & 30 \\
\hline $21,000-30,000$ & 27 & 27 \\
\hline $31,000-40,000$ & 34 & 34 \\
\hline $41,000-50,000$ & 9 & - \\
\hline $51,000-60,000$ & 0 & - \\
\hline$>60,000$ & 0 & 100 \\
\hline Amount & 100 & \\
\hline Average (IDR) & $31,000-40,000$ \\
\hline Assumed Value of WTP (IDR) & 40,000 \\
\hline
\end{tabular}

Ability to Pay (ATP) was determined from the non-food expenditure. ATP was defined by using $5 \%$ of the non-food spending of the population. If the non-food expenditure of the population were assumed to be IDR 2,500,000 based on the maximum expense of the highest percentage, therefore the ability to pay the population would be IDR 125,000 . Table 4 indicated the number of expenditures in percentage. It was found $47 \%$ of respondent spent their income on non-food spending at 2-2.5 thousand rupiahs per month. Based on the analysis of the ATP and WTP above, it can be concluded that the value of ATP is higher than the value of WTP (IDR 125,000 > IDR 40,000). This occurs when users of the service have a relatively high income, but the willingness to pay for utility services is still low. 
Table 3. Percentage of revenues and expenditures based on users' income.

\begin{tabular}{|c|c|c|}
\hline Amount (IDR) & Revenues (\%) & Expenditures (\%) \\
\hline $3,000,000-3,500,000$ & 0 & 33 \\
\hline $3,500,000-4,000,000$ & 12 & 9 \\
\hline $4,000,000-4,500,000$ & 3 & 13 \\
\hline $4,500,000-5,000,000$ & 25 & 30 \\
\hline$>5,000,000$ & 60 & 15 \\
\hline
\end{tabular}

Table 4. Users' expenditure for non-food expenditure based on the survey.

\begin{tabular}{|c|c|}
\hline Expenditure (IDR) & Percentage (\%) \\
\hline $1,000,000-1,500,000$ & $8 \%$ \\
\hline $1,500,000-2,000,000$ & $23 \%$ \\
\hline $2,000,000-2,500,000$ & $47 \%$ \\
\hline $2,500,000-3,000,000$ & - \\
\hline $3,000,000-3,500,000$ & $10 \%$ \\
\hline $3,500,000-4,000,000$ & $12 \%$ \\
\hline
\end{tabular}

\subsection{Economic feasibility analysis}

Table 5. Variables used for NPV, BCR, and IRR

\begin{tabular}{|c|c|}
\hline Variables & Amount (IDR) \\
\hline \multicolumn{2}{|l|}{ Costs: } \\
\hline Land Acquisition Costs & $202,500,000$ \\
\hline Construction Costs & $8,274,038,800$ \\
\hline O\&M Costs (rates per year 7\%) & $224,450,645$ \\
\hline \multicolumn{2}{|l|}{ Revenues: } \\
\hline Number of users & 2,500,000 (IDR), 463 unit \\
\hline Rates based on WTP (Alternative 1) & 40,000 IDR \\
\hline Rates based on ATP (Alternative 2) & $125,000 \mathrm{IDR}$ \\
\hline Interest rate & $7 \%$ \\
\hline Concession Time & 20 years \\
\hline
\end{tabular}

The economic feasibility of the planned WWTP construction at the Residential Growth Areas at Muara Enim was analyzed based on the benefit and cost analysis to be incurred 
over 20 years. The criteria used for economic feasibility analysis are Net Present Value (NPV), Benefit Cost Ratio (BCR), and Internal Rate of Return (IRR).

Table 5 presented the variables used to determine the initial economic feasibility analysis which consists of elements for costs and benefits analysis. A 20-year concession was taken as an example as a considérable time for a project to make a profit. The WWTP project is typically community-based and unfeasible investment from the perspective of private sectors since it tends to involve community participation.

Table 6. Cash flow for Net Present Value (NPV).

\begin{tabular}{|c|c|c|c|c|c|}
\hline Year & Benefit (IDR) & Cost (IDR) & Net Benefit (IDR) & DF (7 \%) & PV Net Benefit (IDR) \\
\hline 0 & $1,156,725,007$ & $8,476,538,800$ & $7,319,813,792$ & 1.00 & $7,319,813,792$ \\
\hline 1 & $709,564,617$ & $224,450,645$ & $485,113,972$ & 0.93 & $453,377,544$ \\
\hline 2 & $765,337,793$ & $240,162,190$ & $525,175,603$ & 0.87 & $458,708,710$ \\
\hline 3 & $825,494,849$ & $256,973,543$ & $568,521,306$ & 0.81 & $464,082,735$ \\
\hline 4 & $890,380,369$ & $274,961,691$ & $615,418,678$ & 0.76 & $469,499,962$ \\
\hline 5 & $960,366,018$ & $294,209,009$ & $666,157,009$ & 0.71 & $474,960,740$ \\
\hline 6 & $1,035,852,677$ & $314,803,640$ & $721,049,037$ & 0.66 & $480,465,419$ \\
\hline 7 & $1,117,272,736$ & $336,839,895$ & $780,432,841$ & 0.62 & $486,014,350$ \\
\hline 8 & $1,205,092,572$ & $360,418,688$ & $844,673,884$ & 0.58 & $491,607,891$ \\
\hline 9 & $1,299,815,220$ & $385,647,996$ & $914,167,224$ & 0.54 & $497,246,399$ \\
\hline 10 & $1,401,983,255$ & $412,643,356$ & $989,339,898$ & 0.50 & $502,930,237$ \\
\hline 11 & $1,512,181,897$ & $441,528,390$ & $1,070,653,506$ & 0.47 & $508,659,768$ \\
\hline 12 & $1,631,042,370$ & $472,435,378$ & $1,158,606,992$ & 0.44 & $514,435,360$ \\
\hline 13 & $1,759,245,511$ & $505,505,854$ & $1,253,739,656$ & 0.41 & $520,257,384$ \\
\hline 14 & $1,897,525,670$ & $540,891,264$ & $1,356,634,405$ & 0.38 & $526,126,212$ \\
\hline 15 & $2,046,674,922$ & $578,753,653$ & $1,467,921,269$ & 0.36 & $532,042,221$ \\
\hline 16 & $2,207,547,599$ & $619,266,408$ & $1,588,281,190$ & 0.33 & $538,005,790$ \\
\hline 17 & $2,381,065,184$ & $662,615,057$ & $1,718,450,127$ & 0.31 & $544,017,301$ \\
\hline 18 & $2,568,221,594$ & $708,998,111$ & $1,859,223,482$ & 0.29 & $550,077,140$ \\
\hline 19 & $2,770,088,865$ & $758,627,979$ & $2,011,460,886$ & 0.27 & $556,185,696$ \\
\hline 20 & $2,987,823,301$ & $811,731,937$ & $2,176,091,364$ & 0.25 & $562,343,360$ \\
\hline \multicolumn{5}{|c|}{ Net Present Value (NPV) } & $\begin{array}{l}\text { Net Present Value } \\
\text { (NPV) }\end{array}$ \\
\hline \multirow{2}{*}{\multicolumn{5}{|c|}{ Decision }} & $\mathrm{NPV}>0$ \\
\hline & & & & & Feasible \\
\hline
\end{tabular}


Table 7. Cash flow for Benefit Cost Ratio (BCR).

\begin{tabular}{|c|c|c|c|c|c|}
\hline Year & Benefit (IDR) & Cost (IDR) & DF (7\%) & PV Benefit (IDR) & PV Cost (IDR) \\
\hline 0 & $1,156,725,007$ & $8,476,538,800$ & 1.00 & $1,156,725,007$ & $8,476,538,800$ \\
\hline 1 & $709,564,617$ & $224,450,645$ & 0.94 & $663,144,502$ & $209,766,957$ \\
\hline 2 & $765,337,793$ & $240,162,190$ & 0.87 & $668,475,668$ & $209,766,957$ \\
\hline 3 & $825,494,849$ & $256,973,543$ & 0.82 & $673,849,693$ & $209,766,957$ \\
\hline 4 & $890,380,369$ & $274,961,691$ & 0.76 & $679,266,920$ & $209,766,957$ \\
\hline 5 & $960,366,018$ & $294,209,009$ & 0.71 & $684,727,698$ & $209,766,957$ \\
\hline 6 & $1,035,852,677$ & $314,803,640$ & 0.67 & $690,232,376$ & $209,766,957$ \\
\hline 7 & $1,119,272,736$ & $336,839,895$ & 0.62 & $695,781,308$ & $209,766,957$ \\
\hline 8 & $1,205,092,572$ & $360,418,688$ & 0.58 & $701,374,849$ & $209,766,957$ \\
\hline 9 & $1,299,815,220$ & $385,647,996$ & 0.54 & $707,013,357$ & $209,766,957$ \\
\hline 10 & $1,401,983,255$ & $412,643,356$ & 0.51 & $712,697,195$ & $209,766,957$ \\
\hline 11 & $1,512,181,897$ & $441,528,390$ & 0.48 & $718,426,726$ & $209,766,957$ \\
\hline 12 & $1,631,042,370$ & $472,435,378$ & 0.44 & $724,202,318$ & $209,766,957$ \\
\hline 13 & $1,759,245,511$ & $505,505,854$ & 0.42 & $730,024,342$ & $209,766,957$ \\
\hline 14 & $1,897,525,670$ & $540,891,264$ & 0.39 & $735,893,170$ & $209,766,957$ \\
\hline 15 & $2,046,674,922$ & $578,753,653$ & 0.36 & $741,809,179$ & $209,766,957$ \\
\hline 16 & $2,207,547,599$ & $619,266,408$ & 0.34 & $747,772,748$ & $209,766,957$ \\
\hline 17 & $2,381,065,184$ & $662,615,057$ & 0.32 & $753,784,259$ & $209,766,957$ \\
\hline 18 & $2,568,221,594$ & $708,998,111$ & 0.30 & $759,844,098$ & $209,766,957$ \\
\hline 19 & $2,770,088,865$ & $758,627,979$ & 0.28 & $765,952,654$ & $209,766,957$ \\
\hline 20 & $2,987,823,301$ & $811,731,937$ & 0.26 & $772,110,318$ & $209,766,957$ \\
\hline & & lount & & $15,483,108,396$ & $12,671,877,958$ \\
\hline \multicolumn{5}{|c|}{ Benefit Cost Ratio (BCR) } & 1.22 \\
\hline \multirow{2}{*}{\multicolumn{5}{|c|}{ Decision }} & $\mathrm{BCR}>1$ \\
\hline & & & & & Feasible \\
\hline
\end{tabular}

\subsubsection{Net Present Value (NPV)}

Net present value (NVP) was determined for 20 years concession time as seen in Table 6 . NPV was also measured based on the values of WTP to define the tariff determination. The alternatives rates were IDR 40,000 and IDR 125,000. The NPV of rate IDR 40,000 were not economically feasible, resulting on NPV less than $0(\mathrm{NPV}=$ negative IDR 
6,794,100,586). Meanwhile, the alternative 2 which uses rate of IDR 125,000 produced positive NPV (NPV = IDR 2,811,230,437), indicating the WWTP development plan is worth to be implemented.

\subsubsection{Benefit- Cost Ratio (BCR)}

Similar to NPV, Benefit Cost Ratio (BCR) was also determined using two alternatives. Alternative 1 was found to be not feasible $(\mathrm{BCR}=0.46)$, while alternative 2 was found to be feasible $(\mathrm{BCR}=1.22)$. The detail calculation of $\mathrm{BCR}$ for 20 years is shown in Table 7 .

\subsubsection{Internal Rate of Return (IRR)}

IRR values were obtained by comparing the value of the Net Present Value (NPV) interest rates prevailing in the market (7\%) and Net Present Value (NPV) benchmark interest rate (12\%). The IRR for alternative 1 and 2 were negative $144 \%$ and $10.75 \%$ respectively. The IRR on alternative 1 was less than $7 \%$ and was found to be not feasible. In the second alternative IRR value was greater than $7 \%$, indicating to be feasible. Table 8 shows the summary of Net Present Value (NPV), Benefit Cost Ratio (BCR), and Internal Rate of Return (IRR) based on two alternatives. It was clear that tariffs of IDR 125,000 were found to be more feasible compared to tariffs of IDR 40,000.

In line with the study of [10], the economic feasibility study is required to determine the benefits compared to costs. This study found that the types of technology to treat the wastewater were significantly influenced the construction and operational costs. However, the project was found to be feasible $(\mathrm{BCR}=2.13)$ during 20 years concession. It can be concluded that the WWTP project has promising benefits which are mostly based on community participation.

Table 8. Assessment for each alternative.

\begin{tabular}{|r|c|c|c|c|}
\hline Alternatives & Criteria & $\begin{array}{c}\text { Criteria of } \\
\text { assessment }\end{array}$ & Results & Decisions \\
\hline \multirow{2}{*}{$\begin{array}{c}\text { I.Using Rates } \\
\text { IDR } 40,000\end{array}$} & $\mathrm{NPV}$ & $\mathrm{NPV}>0$ & $-6,794,100,586$ (IDR) & Not feasible \\
\cline { 2 - 5 } & $\mathrm{BCR}$ & $\mathrm{BCR}>1$ & 0.46 & Not feasible \\
\cline { 2 - 5 } & $\mathrm{IRR}$ & $\mathrm{IRR}>7 \%$ & $-144 \%$ & Not feasible \\
\hline \multirow{3}{*}{$\begin{array}{c}\text { II. Using Rates } \\
\text { IDR } 125,000\end{array}$} & $\mathrm{NPV}$ & $\mathrm{NPV}>0$ & $2,811,230,437$ (IDR) & Feasible \\
\cline { 2 - 5 } & $\mathrm{BCR}$ & $\mathrm{BCR}>1$ & 1.22 & Feasible \\
\cline { 2 - 5 } & $\mathrm{IRR}$ & $\mathrm{IRR}>7 \%$ & $10.75 \%$ & Feasible \\
\hline
\end{tabular}

\subsubsection{Sensitivity analysis}

Sensitivity analysis was used to determine the influence of one variable to the other variable. Sensitivity analysis was conducted by comparing the ranges of different interest rates to assess NPV. As seen in Table 9, NPV will be positive with interest rates of $7.75 \%$ $9.25 \%$ and will be negative with discount rates up to $9.75 \%$. 
Tabel 9. Net Present Value (NPV) for different Interest Rates.

\begin{tabular}{|c|c|}
\hline Interest Rates (\%) & NPV (IDR) \\
\hline 7.75 & $1,286,337,080$ \\
\hline 8.25 & $862,156,458$ \\
\hline 8.75 & $466,176,803$ \\
\hline 9.25 & $96,228,469$ \\
\hline 9.75 & $(249,674,294)$ \\
\hline 10.25 & $(573,350,121)$ \\
\hline 10.75 & $(876,465,688)$ \\
\hline 11.25 & $(1,295,897,207)$ \\
\hline
\end{tabular}

\section{Conclusions}

This paper discussed the economic analysis of possible rates determination based on the ability to pay (ATP) and willingness to pay (WTP) of users of wastewater treatment plant (WWTP) at Muara Enim, South Sumatra. Furthermore, this paper also highlighted the sensitivity of NPV for different scenarios using different discount rates. The economic feasibility of the planned WWTP construction at the Residential Growth Areas at Muara Enim was analyzed based on the benefit and cost analysis to be incurred over 20 years. It was found that the values of ATP and WTP are IDR 125,000 and 40,000 respectively. Using the higher values of ATP, the NPV and BCR are found to be economically feasible. For the sensitivity analysis, NPV resulted positive with interest rates of $7.75-9.25 \%$, and negative with discount rates up to $9.75 \%$. Therefore, to develop WWTP, it is expected subsidies from the local government could help accelerate the WWTP construction as well as its operation and maintenance during its lifecycle.

\section{References}

1. H. Gunatilake, J. Yang, S. Pattanayak, C. Van Den Berg, ERD Technical note series 19 (2006)

2. D. Hensher, N. Shore, K. Train, Env. and Res. Economics 32, 4 (2005)

3. S.M. Kerstens, M. Spiller, I. Leusbrock, G. Zeeman, Sci. Total Env. 550 (2016)

4. S.M. Kerstens, I. Leusbrock, G. Zeeman, Sci. Total Env. 530-531 (2015)

5. C. Munusami, J. Othman, S.M. Ismail, C. Siwar. Int. J. of Bus. and Soc. 17, 2 (2016)

6. W. Piao, Y. Kim, H. Kim, M. Kim, C. Kim, J. Clean. Prod. 113 (2016)

7. United Nations. The World's Cities in 2016 (2016)

8. D. Vouk, D. Malus, I. Halkijevic, Expert Sys. Appl. 38, 8 (2011)

9. K.G. Willis, R. Scarpa, M. Acutt, Water Resources Res. 41 (2005)

10. R. Nugroho, A. Rifai. Jurnal Teknik Lingkungan 13, 3 (2012)

11. Rahmanissa, A. Slamet. Jurnal Teknik ITS Nopember 6, 2 (2017) 